\title{
High rates of complications in advanced stage gastric cancer after laparoscopic gastrectomy
}

\author{
Sang-Ho Jeong ${ }^{1,2,3}$, Ji-Ho Park ${ }^{1,2,3}$, Sang-Kyung Choi ${ }^{1,2,3}$, Soon-Chan Hong ${ }^{1,2,3}$, Eun-Jung Jung ${ }^{1,2,3}$, Young-Tae Ju ${ }^{1,2,3}$, \\ Chi-Young Jeong ${ }^{1,2,3}$, Miyeong Park', Woo-Song Ha ${ }^{1,2,3}$, Young-Joon Lee ${ }^{1,2,3}$ \\ 'Department Surgery, Gyeongsang National University School of Medicine, Jinju; \\ ${ }^{2}$ Gyeongnam Regional Cancer Center, Jinju; \\ ${ }^{3}$ Institue of Health Sciences, Gyeongsang National University, Jinju; \\ ${ }^{4}$ Department Anesthesiology, Gyeongsang National University Changwon Hospital, Gyeongsang National University School of Medicine, Changwon, \\ Korea
}

Purpose: The inclusion criteria for laparoscopic gastrectomy have recently been expanded, and this has led to an increase in the number of publications describing the laparoscopic treatment of advanced gastric cancer. The aim of this study was to evaluate morbidity in advanced stage gastric cancer (ASGC; tumor, node, metastasis [TNM] stage II-III) compared with that in early stage gastric cancer (ESGC; TNM stage I) in patients undergoing laparoscopic assisted distal gastrectomy (LADG).

Methods: The clinical data of 448 consecutive patients who underwent LADG with RO resection for gastric cancer at the Gyeongsang National University Hospital were retrospectively analyzed.

Results: The morbidity and mortality rates for radical distal gastrectomy were $20.3 \%(91 / 448)$ and $0.2 \%(1 / 448)$, respectively. Wound problems were the most common complication $(4.7 \%, n=21)$, followed by leakage $(4.5 \%, n=20)$, and postoperative bleeding $(3.8 \%, n=17)$. We found ASGC had higher frequencies of postoperative ileus ( $0.8 \%$ vs. $5.4 \%)$, wound problems (3.1\% vs. $10.9 \%)$, and pulmonary complications (4\% vs. $7 \%$ ) than ESGC in the LADG $(P<0.05)$.

Conclusion: Among patients who underwent LADG, ASGC patients had higher rates of postoperative ileus and wound and pulmonary complications than ESGC patients. ASGC patients should be closely monitored for these complications after LADG.

Keywords: Stomach neoplasm, Gastrectomy, Laparoscopy, Postoperative complication, lleus

\section{INTRODUCTION}

Inclusion criteria for laparoscopic gastrectomy have recently been expanded, and this has led to an increase in the number of publications describing the laparoscopic treatment of advanced stage gastric cancer (ASGC) [1-4]. Gastric cancer is the fourth most common type of cancer and has the second highest mortality rate worldwide. Nearly 1 million new cases are diagnosed each year.

Received: Oct 6, 2017 Accepted: Dec 18, 2017

Correspondence to: Young-Joon Lee

Department of Surgery, Gyeongsang National University School of Medicine, Gyeongsang National University Hospital, 79 Gangnam-ro, Jinju 52727, Korea

Tel: +82-55-750-8446, Fax: +82-55-757-5442

E-mail: yjleegnu@gmail.com

Copyright ( $($ Korean Society of Surgical Oncology

This is an Open Access article distributed under the terms of the Creative Commons Attribution Non-Commercial License (http://creativecommons.org/licenses/by-nc/4.0) which permits unrestricted non-commercial use, distribution, and reproduction in any medium, provided the original work is properly cited.
Although the incidence and mortality for gastric cancer in Korea and Japan have gradually decreased, it remains the second most frequent cause of death in Korea [5].

Several studies have reported that laparoscopic surgery requires a smaller incision, is less painful, and has a more rapid recovery rate and has decreased morbidity rates than open surgery $[1-4,6,7]$. However, a few studies have compared laparoscopic surgery for early stage gastric cancer (ESGC) and ASGC because surgery for advanced gastric cancer is less frequent than for early gastric cancer. Our center started surgery for the treatment of advanced gastric cancer since 2005. We have already reported that laparoscopic gastrectomy is a safe and feasible procedure even for advanced gastric cancer [8]. In this study, we aimed to evaluate morbidity in ASGC (American Joint Committee on Cancer [AJCC], tumor node metastasis [TNM] stage 7th edition; TNM stage II-IV) compared with ESGC (TNM stage I) in patients undergoing laparoscopic assisted distal gastrectomy (LADG). 


\section{METHODS}

We retrospectively analyzed the clinical data from 448 consecutive patients who underwent LADG with R0 resection for gastric cancer at the Gyeongsang National University Hospital between January 2005 and June 2012. All data concerning sex, age, duration of postoperative hospital stay, operative risk, American Society of Anesthesiologists score, operative method (approach method, resection, and combined resection), and postoperative morbidity were collected prospectively.

The inclusion criteria of this study were as follows: histological proven primary gastric adenocarcinoma in the gastric middle and lower body; no evidence of other distant metastasis; and R0 resection. The decision to undergo open gastrectomy or LADG was ultimately made by the patient after sufficient information was provided. However, we recommended LADG to all patients who fulfilled the following inclusion criteria: the presence of adenocarcinoma was proven by histopathological analysis of biopsy material, the tumor was less than $5 \mathrm{~cm}$ in diameter, and preoperative computed tomography (CT) or endoscopic ultrasound revealed a clinical stage below T3N1 (subserosa invasion, LN 1-6 metastasis; defined according to AJCC TNM 6th). We excluded patients with the following: active double cancer (synchronous and metachronous double cancer within 5 disease-free years), carcinoma in situ (lesions equal to intraepithelial or intramucosal cancer), total gastrectomy and wedge resection methods, gastric cancer recurrence, or a history of gastrectomy.

\section{Surgical procedures}

In all LADG, when preoperative diagnosis using gastrofibroscopy and spiral CT scans showed ESGC, then subtotal gastrectomy, partial omentectomy, and D1+ lymph node dissection (1, 3, 4sb, 4d, 5, 6, 7, 8a, 9) were performed [9]. However, if ASGC or lymph node metastasis were detected, then total omentectomy and D2 lymph node dissection (1, 3, 4sb, 4d, 5, 6, 7, 8a, 9, 11p, and 12a) were performed. During the operation, we inspect the tumor serosa invasion, and lymph node metastasis. If it is expected as serosal invasion or lymph node metastasis more than 6 lymph node, and we performed open conversion. Lymph node station numbers were scored according to the Japanese Classification of Gastric Carcino$\mathrm{ma}$ (1998) [10]. Gastric resection and determination of the resection area of the lymph node stations were performed according to the Japanese Gastric Cancer Association guidelines (2002 and 2010) $[9,11]$. For reconstruction, extracorporeal Billroth I or extracorporeal Billroth II using upper midline or right subcostal minilaparotomy was performed from January 2005 to June 2009 [12]. We performed the intracorporeal Billroth II after subtotal gastrec- tomy from July 2009 to 2012.

We defined postoperative morbidity as a complication that occurs after surgery that delays discharge or results in the patient requiring treatment in an outpatient clinic after discharge. The following definitions, which were derived from our earlier studies and other studies [13-15], were used to assess complications: (1) anastomotic leakage, defined as dehiscence confirmed by contrast radiography; (2) an intraabdominal abscess, defined as the presence of septic fluid in the abdominal cavity that resulted in pyrexia (body temperature $>38^{\circ} \mathrm{C}$ ) and was confirmed by ultrasonography or CT; (3) acute pancreatitis, defined as the postoperative level of amylase increasing more than $150 \mathrm{IU}$; (4) postoperative bleeding, defined as a condition requiring transfusion and confirmed by gastrofibroscopy or through intervention; (5) paralytic ileus, defined as delayed oral feeding owing to delayed recovery of bowel movement as demonstrated by gaseous distension without an air-fluid level on a plain radiograph; (6) intestinal obstruction, defined as a mechanical obstruction with an air-fluid level and obstruction site apparent during CT; (7) a wound problem, defined as the presence of serous fluid or pus at the incision site leading to delayed suture removal or wound resuture; (8) pulmonary complication, defined as the presence of pleural effusion, empyema, pneumonia, or pneumothorax on a plain chest radiograph or CT scan; (9) hepatic complication, defined as abnormality of liver function test (total bilirubin $>1.3 \mathrm{mg} / \mathrm{dL}$ or/and aspartate aminotransferase/alanine transaminase levels more than doubled); (10) cardiac complications, defined as the postoperative presence of a symptom, a laboratory test result, or an electrocardiogram indicative of myocardial infarction, cardiac angina, or arrhythmia; (11) vascular complication, defined as a patient's need for anticoagulation after the diagnosis of arterial or venous thrombus or embolism on CT or ultrasound; (12) renal complication, defined as the presence of symptoms or laboratory blood test results indicative of acute renal failure [15].

We defined the patients with TNM stage I as the ESGC and TNM stage II-III as the ASGC. This study was approved by the Institutional Review Board of Gyeongsang National University Hospital (GNUH IRB no. 2009-54).

\section{Statistical analysis}

Student's t-test and $\chi^{2}$ test were used for statistical analyses, and a value of $\mathrm{P}<0.05$ (two-sided) was considered statistically significant. SPSS ver. 18.0 (SPSS Inc., Chicago, IL, USA) was used for the statistical analyses. 


\section{RESULTS}

\section{Patient demographics}

The mean patient age was $60.7 \pm 11.3$ years. The male-to-female ratio was 2.1:1. The most frequent tumor location was the gastric low third $(\mathrm{n}=395,89.8 \%)$, gastric middle third $(\mathrm{n}=46,10 \%)$ followed by the gastric upper third $(n=3,0.7 \%)$. The mean tumor size was $2.8 \pm 1.9 \mathrm{~cm}$. Analysis of the TNM stages showed that 79.5\% $(\mathrm{n}=356), 12.7 \%(\mathrm{n}=57)$, and $7.8 \%(\mathrm{n}=35)$ of the patients had stage I, II, and III disease, respectively. The mean operation time was $342.9 \pm 91.5$ minutes. The mean duration of postoperative hospital stay was $15.3 \pm 12.7$ days. Regarding the reconstruction type, Billroth type I, Billroth type II, and Roux en Y gastrojejunostomy were performed in $45.1 \%$ (202), 54.7\% (245), and 0.2\% $(\mathrm{n}=1)$ patients, respectively. Combined organ resection was performed in $10.7 \%(\mathrm{n}=48)$ of all cases.

The overall morbidity and mortality rates for LADG were 20.3\% (91/448) and $0.2 \%$ (1/448), respectively. The most frequent complications were wound problems $(\mathrm{n}=21,4,7 \%)$, anastomotic leakage $(\mathrm{n}=20,4.5 \%)$, and postoperative bleeding $(\mathrm{n}=17,3.8 \%)$, followed by intraabdominal abscess $(\mathrm{n}=15,3.3 \%)$, pulmonary complications $(\mathrm{n}=11,2.5 \%)$, paralytic ileus $(\mathrm{n}=8,1.8 \%)$, acute pancreatitis $(\mathrm{n}=4,0.9 \%)$, cardiac problems $(\mathrm{n}=4,0.9 \%)$, and hepatic complications ( $\mathrm{n}=3,0.7 \%)$. We classified the complications using the Accordion Severity Classification of Postoperative Complications; Expanded Classification ${ }^{21}$ : no complication ( 0$)(\mathrm{n}=351,78.3 \%)$, mild complication (1) $(\mathrm{n}=40,8.9 \%)$, moderate complication (2) $(\mathrm{n}=23$, $5.1 \%)$, severe complication with intervention $(3)(\mathrm{n}=27,6.0 \%)$, severe complication with reoperation (4) $(\mathrm{n}=5,1.1 \%)$, organ system failure $(5)(\mathrm{n}=1,0.2 \%)$, and death $(6)(\mathrm{n}=1,0.2 \%)$.

\section{Higher incidence of paralytic ileus, wound problems, and pulmonary complications in the advanced stage LADG groups}

We analyzed morbidity and mortality in the early stage group (stage I) and the advanced stage group (stage II-III) in LADG. The incidences of paralytic ileus (stage I $=0.8 \%$ vs. stage II-III $=5.4 \%$, $\mathrm{P}=0.01$ ), wound problems ( $3.1 \%$ vs. $10.9 \%, \mathrm{P}<0.01)$, and pulmonary complications ( $4 \%$ vs. $7 \%, \mathrm{P}<0.01$ ) were significantly higher in the advanced stage group than in the early stage group. There were no differences in anastomotic leakage, intraabdominal abscess, acute pancreatitis, postoperative bleeding, urologic complications, hepatic complications, cardiac complications, or mortality $(\mathrm{P} \geq 0.05)$ (Table 1).

There were statistically significant differences in mean retrieved lymph nodes (stage $\mathrm{I}=22.4$ vs. stage $\mathrm{II}-\mathrm{III}=30.8, \mathrm{P}<0.01$ ), and operation time (stage I = 329 minutes vs. stage II- III = 395 min-
Table 1. Differences in morbidity between stage I vs. stage II-III in laparoscopic assisted distal gastrectomy groups

\begin{tabular}{lrccr} 
Morbidity \& mortality & $\begin{array}{c}\text { Total } \\
\text { case }\end{array}$ & $\begin{array}{c}\text { Stage I (\%) } \\
(\mathrm{n}=356)\end{array}$ & $\begin{array}{c}\text { Stage II-III } \\
(\%)(\mathrm{n}=92)\end{array}$ & P-value \\
\hline Anastomotic leakage & 20 & $14(3.9)$ & $6(6.5)$ & 0.26 \\
Intraabdominal abscess & 15 & $13(3.6)$ & $2(2.2)$ & 0.74 \\
Acute pancreatitis & 4 & $4(1.1)$ & 0 & 0.58 \\
Postoperative bleeding & 17 & $14(3.9)$ & $3(3.3)$ & 1.00 \\
Paralytic ileus & 8 & $3(0.8)$ & $5(5.4)$ & 0.01 \\
Wound problem & 21 & $11(3.1)$ & $10(10.9)$ & $<0.01$ \\
Pulmonary complication & 11 & $4(1.1)$ & $7(7.6)$ & $<0.01$ \\
Hepatic complication & 3 & $1(0.3)$ & $2(2.2)$ & 0.10 \\
Cardiac problem & 4 & $2(0.6)$ & $2(1.1)$ & 0.49 \\
Other complication & 19 & $14(3.9)$ & $5(5.4)$ & 0.56 \\
Mortality & 1 & 0 & $1(1.1)$ & 0.20 \\
\hline
\end{tabular}

American Joint Committee on Cancer, Tumor Node Metastasis (TNM) stage 7th edition.

Table 2. Differences in clinicopathologic features between stage I vs. stage II-III in the laparoscopic assisted distal surgery group

\begin{tabular}{lccc}
\hline Clinicopathologic features & Stage I & Stage II-IV & P-value \\
\hline Retrieved lymph node number & $22.4 \pm 10.3$ & $30.8 \pm 12.5$ & $<0.01$ \\
Operation time (min) & $329 \pm 82$ & $395 \pm 104$ & $<0.01$ \\
Hospital stay (day) & $14.8 \pm 12.4$ & $17.5 \pm 13.6$ & 0.07 \\
Time to first flatus (day) & $3.3 \pm 1.1$ & $3.5 \pm 1.1$ & 0.07 \\
\hline
\end{tabular}

utes, $\mathrm{P}<0.01$ ) in the advanced stage group with LADG. This group also had a longer hospital stay (stage $\mathrm{I}=14.8$ days vs. stage II$\mathrm{III}=17.5$ days, $\mathrm{P}=0.07$ ) and time to the first flatus (stage $\mathrm{I}=3.3$ days vs. stage $\mathrm{II}-\mathrm{III}=3.5$ days, $\mathrm{P}=0.07$ ), but the differences were not statistically different (Table 2 ).

\section{DISCUSSION}

The perioperative risk factors for postoperative morbidity in stomach cancer surgery have frequently been reported [15]. A significant association between prolonged operation time and excessive blood loss and postoperative morbidity has been reported in elderly patients [16]. Old age ( $\geq 65$ years), advanced tumor stage, and combined organ resection were identified as significant risk factors for postoperative mortality and morbidity [13,17-19]. A recent study found a significant correlation with postoperative morbidity for $\mathrm{pa}-$ tients aged $\geq 70$ years with hypertension or liver cirrhosis, and we have reported that underlying heart disease or chronic liver disease are significant independent risk factors for postoperative morbidity $[2,15]$. With regard to laparoscopic surgery, Kim et al. [14] reported that the surgeon's relative inexperience ( $<50$ cases) and the patient having $>1$ comorbidity were important factors for postoperative 
morbidity; Bo et al. [20] reported that intraabdominal organ injury (colon, liver, spleen, cystic artery, or biliary tract) during surgery for advanced gastric cancer and duodenal stump leakage, intraabdominal bleeding, acute pancreatitis, and delayed gastric emptying were important factors for postoperative morbidity

We found that paralytic ileus, wound problems, and pulmonary complications were high in the ASGC that underwent LADG. The reason for the difference between the ESGC and the ASGC for LADG but not open gastrectomy is unknown. In our opinion, the causes of the differences in incidence rates were differences in the operation area and time. The operation areas for open surgery in the early stage group and advanced stage group were same procedure, because both groups required total omentectomy and the same D2 LN dissection procedure. However, there were differences in laparoscopic surgery with additional total omentectomy (approximately 30-40 minutes) and LN 11p, 12a (approximately 2040 minutes). The complications included increased wider operation field, more difficult dissection of LN 11p and 12a, and longer operation times (mean, 62 minutes) for laparoscopic surgery. Paralytic ileus is associated longer tissue handling times, and pulmonary complications and wound problems are associated with longer operation time. Wound problems in advanced stage group are also associated with larger wound sizes because of the bulky specimen due to the whole omentum.

In conclusion, we found that ASGC patients had higher rates of postoperative ileus and wound and pulmonary complications than ESGC patients following LADG. ASGC patients should be monitored closely for these complications after LADG.

\section{CONFLICT OF INTEREST}

No potential conflict of interest relevant to this article was reported.

\section{ACKNOWLEDGMENTS}

The authors would like to thank Young-Suk Kim, RN for conducting retrospective and prospective data collection assist.

\section{REFERENCES}

1. Hur H, Jeon HM, Kim W. Laparoscopy-assisted distal gastrectomy with D2 lymphadenectomy for T2b advanced gastric cancers: three years' experience. J Surg Oncol 2008;98:515-9.

2. Hwang SH, Park do J, Jee YS, Kim HH, Lee HJ, Yang HK, et al. Risk factors for operative complications in elderly patients during laparoscopy-assisted gastrectomy. J Am Coll Surg 2009;208:186-92.

3. Lee JH, Kim YW, Ryu KW, Lee JR, Kim CG, Choi IJ, et al. A phase-
II clinical trial of laparoscopy-assisted distal gastrectomy with D2 lymph node dissection for gastric cancer patients. Ann Surg Oncol 2007;14:3148-53.

4. Song KY, Kim SN, Park CH. Laparoscopy-assisted distal gastrectomy with D2 lymph node dissection for gastric cancer: technical and oncologic aspects. Surg Endosc 2008;22:655-9.

5. Lee HJ, Yang HK, Ahn YO. Gastric cancer in Korea. Gastric Cancer 2002;5:177-82.

6. Lee J, Kim W. Long-term outcomes after laparoscopy-assisted gastrectomy for advanced gastric cancer: analysis of consecutive 106 experiences. J Surg Oncol 2009;100:693-8.

7. Tokunaga M, Hiki N, Fukunaga T, Nohara K, Katayama H, Akashi Y, et al. Laparoscopy-assisted distal gastrectomy with D2 lymph node dissection following standardization: a preliminary study. J Gastrointest Surg 2009;13:1058-63.

8. Jeong SH, Lee YJ, Park ST, Choi SK, Hong SC, Jung EJ, et al. Risk of recurrence after laparoscopy-assisted radical gastrectomy for gastric cancer performed by a single surgeon. Surg Endosc 2011;25: 872-8.

9. Japanese Gastric Cancer Association. Japanese gastric cancer treatment guidelines 2010 (ver. 3). Gastric Cancer 2011;14:113-23.

10. Japanese Gastric Cancer Association. Japanese Classification of Gastric Carcinoma: 2nd English Edition. Gastric Cancer 1998;1: 10-24

11. Nakajima T. Gastric cancer treatment guidelines in Japan. Gastric Cancer 2002;5:1-5.

12. Joo YT, Moon HG, Lee SH, Jeong CY, Jung EJ, Hong SC, et al. Laparoscopy-assisted distal gastrectomy with intracorporeal Billroth I stapled anastomosis using a hand access device for patients with gastric cancer. Surg Endosc 2007;21:859-62.

13. Park DJ, Lee HJ, Kim HH, Yang HK, Lee KU, Choe KJ. Predictors of operative morbidity and mortality in gastric cancer surgery. $\mathrm{Br} \mathrm{J}$ Surg 2005;92:1099-102.

14. Kim MC, Kim W, Kim HH, Ryu SW, Ryu SY, Song KY, et al. Risk factors associated with complication following laparoscopy-assisted gastrectomy for gastric cancer: a large-scale korean multicenter study. Ann Surg Oncol 2008;15:2692-700.

15. Jeong SH, Ahn HS, Yoo MW, Cho JJ, Lee HJ, Kim HH, et al. Increased morbidity rates in patients with heart disease or chronic liver disease following radical gastric surgery. J Surg Oncol 2010; 101:200-4.

16. Habu H, Endo M. Gastric cancer in elderly patients: results of surgical treatment. Hepatogastroenterology 1989;36:71-4.

17. Viste A, Haugstvedt T, Eide GE, Soreide O. Postoperative complications and mortality after surgery for gastric cancer. Ann Surg 1988;207:7-13.

18. McCulloch P, Ward J, Tekkis PP. Mortality and morbidity in gas- 
tro-oesophageal cancer surgery: initial results of ASCOT multicentre prospective cohort study. BMJ 2003;327:1192-7.

19. Bittner R, Butters M, Ulrich M, Uppenbrink S, Beger HG. Total gastrectomy: updated operative mortality and long-term survival with particular reference to patients older than 70 years of age. Ann
Surg 1996;224:37-42.

20. Bo T, Zhihong P, Peiwu Y, Feng Q, Ziqiang W, Yan S, et al. General complications following laparoscopic-assisted gastrectomy and analysis of techniques to manage them. Surg Endosc 2009;23: 1860-5. 